Institutions, Meyer 2-147-JHH, $600 \mathrm{~N}$ Wolfe St, Baltimore, MD 21287).

COMMENT. That the ketogenic diet (KD) works has been established and corroborated by numerous investigators in the past. Is it of practical value in the management of childhood epilepsy is perhaps a more pressing question, given the advent of newer antiepileptic drugs? The above multicenter study, completed primarily in university settings, corroborates once again the partial efficacy of the KD, when introduced under hospitalized supervision, and when patients are followed closely by dietary, nursing, and physician services. Antiepileptic medication must be continued in the majority of patients treated, compounding the cost of dietary services, frequently not covered by health insurance plans.

Despite close supervision, complete control of seizures may be expected in only $10 \%$ of patients and $53 \%$ will have discontinued the diet after one year. Medical intolerance, the restrictive regimen, and insufficient seizure control to justify the demands of the diet are reasons for its withdrawal. Serious side effects, not mentioned in the above report, are the subject of a paper recently published by one of the participant authors and institutions (Ballaban-Gil $\mathrm{K}$ et al. Complications of the ketogenic diet. Epilepsia July 1998;39:744-748; see Ped Neur Briefs Aug 1998;12:6()). In $5(10 \%)$ of 52 children treated with the KD, adverse events included hypoproteinemia, lipemia, hemolytic anemia, and Fanconi's renal tubular acidosis; two patients had severe abnormalities of liver function, one with concomitant thrombocy topenia.

The ketogenic diet may be of value as a short-term therapy in a limited group of children with refractory epilepsy or in those exhibiting serious adverse reactions to AEDs. Its use should perhaps be restricted to research institutions where studies of the mechanism of action of the diet might uncover an essential specific ingredient and further our understanding of seizure pathophysiology (see Progress in Pediatric Neurology, PNB Publ, Vol I, 1991;pp 87-88; Vol III, 1997;pp578-9). To paraphrase the conclusions of an editorial (Roach ES. Alternative neurology. The ketogenic diet. Arch Neurol Nov 1998;55:1403-4), "Those who champion alternative treatments have an obligation to study them thoroughly before promoting them for general use with patients." "They should also be accountable for the cost-effectiveness of their methods." The Mayo Clinic KD protocol, which avoids the necessity for pre-diet starvation and hospitalization of the patient, is in my experience more practical and cost-effective and equally successful (Millichap JG, Jones JD, Rudis BP. Mechanism of the anticonvulsant action of the ketogenic diet. Am I Dis Child 1964;107:593).

\title{
BONE MINERAL DENSITY UNAFFECTED BY ANTIEPILEPTICS
}

The effects of valproic acid (VPA) and carbamazepine (CBZ) on bone mineral density were evaluated in 53 children with primary epilepsy treated for longer than 1 year at the Gulhane Military Academy, Ankara, Turkey. Mean serum levels of VPA and CBZ were 66 and $7 \mathrm{mcg} / \mathrm{ml}$, respectively. Serum levels of calcium and phosphorus were normal. Mineral densities measured by x-ray absorptiometry at L2-L4 were not significantly different from a control group. (Akin R, Okutan V, Sarici U et al. Evaluation of bone mineral density in children receiving antiepileptic drugs. Pediatr Neurol Aug 1998;19:129-131). (Respond: R Akin MD, Department of Pediatrics, Gulhane Military Medical Academy, Ankara, Turkey).

COMMENT. Previous studies have referred to the occurrence of rickets in children taking antiepileptic drugs. A decrease in serum calcium and elevations in alkaline phosphatase (ALP) have been reported, and nonambulatory, handicapped children are at greater risk of rickets. Elevated ALP values, observed 
in $16 \%$ of the VPA and $21 \%$ of CBZ-treated patients, point to an increased risk of rickets and bone fractures in some children. The importance of monitoring calcium intake and bone metabolism of women with epilepsy is stressed in the following articles.

\section{MANAGEMENT OF EPILEPSY ISSUES IN WOMEN}

Management issues for women with epilepsy (WWE) are reviewed by a team of investigators in conjunction with the AAN Quality Standards Subcommittee. A literature search reveals the need for outcome studies as a base for practice recommendations on contraception, folate supplements, vitamin $\mathrm{K}$ use in pregnancy, breast-feeding, metabolic bone disease, catamenial epilepsy, and reproductive endocrine disorders. (Zahn CA, Morrell MJ, Collins SD, Labiner DM, Yerby MS. Management issues for women with epilepsy. A review of the literature. Neurology Oct 1998;51:949-956). (Reprints: Dr Catherine Zahn, The Toronto Hospital, Western Division, 8 Edith Cavell-034, 399 Bathurst St, Toronto, Ontario M5T 2S8, Canada).

Options recommended by the AAN for WWE that might apply in pediatric neurology practice include use of ethinyl estradiol or mestranol (at least $50 \mathrm{mcg}$ ) for women choosing hormonal contraception during treatment with AEDs, and prepregnancy counseling regarding need for folic acid supplements, risks of teratogenic effects of AEDs, and possible withdrawal or change to a safer AED regimen at least 6 months before conception. (American Academy of Neurology. Practice parameter. Management issues for women with epilepsy (summary statement). Neurology Oct 1998;51:944-948). (Reprints: AAN, 1080 Montreal Ave, St Paul, MN 55116).

COMMENT. For pediatric neurologists who treat adolescents and young adults with epilepsy, these counseling suggestions for WWE are a useful resource.

\section{FOSPHENYTOIN IN INFANTS AND CHILDREN}

The pharmacokinetics, safety, and tolerability of fosphenytoin in children from 1 day to 16 years old and the data available from 78 patients in two multicenter studies are reviewed from the Medical College of Virginia Commonwealth University, Richmond, VA. The conversion half-life of fosphenytoin to phenytoin following intravenous administration in 62 patients was $8.3 \mathrm{~min}$ (range, $2.5-18.5 \mathrm{~min}$ ), with no relation to age. Plasma total phenytoin concentrations of $10-40 \mathrm{mcg} / \mathrm{ml}$ were obtained by $15 \mathrm{~min}$. In 16 patients receiving intramuscular fosphenytoin, $5.5 \mathrm{~mL}$, plasma total phenytoin concentrations of 10 $\mathrm{mcg} / \mathrm{mL}$ were reached within $20 \mathrm{~min}$. The equivalent plasma free phenytoin concentration was $1 \mathrm{mcg} / \mathrm{mL}$. IV infusion rates were $0.5-3 \mathrm{mg} \mathrm{PE} / \mathrm{kg} / \mathrm{min}$. IM loading doses ranged from $12-20 \mathrm{mg} \mathrm{PE} / \mathrm{kg}$, administered in one to three sites. Mild bruising, tenderness, swelling, and/or erythema occurred at infusion or injection sites in $3(6 \%)$ of 52 patients with adequate records. Common systemic reactions included emesis, nystagmus, ataxia, and pruritus. (Morton LD. Clinical experience with fosphenytoin in children. I Child Neurol Oct 1998;13(Suppl 1):S19-S22). (Respond: Dr Lawrence D Morton, Department of Pediatric Neurology, Virginia Commonwealth University, Medical College of Virginia Campus, 307 College Street, 7 th floor, Richmond, VA 23219).

COMMENT. The advantages of fosphenytoin over phenytoin for parenteral administration include a $\mathrm{pH}$ closer to neutral, solubility and compatibility with intravenous fluids, and less discomfort and adverse reaction. The higher cost of fosphenytoin cf phenytoin is offset by the lower rates of complications and 